\title{
Understanding switching behavior of mobile payment enabled transportation apps: A push-pull-mooring perspective
}

\author{
Qiunan Zhang, University of Memphis, qzhang4@memphis.edu \\ Colin G. Onita, San Jose State University, colin.onita@sjsu.edu \\ M. Shane Banks, University of North Alabama, mbanks@una.edu \\ Xihui Zhang, University of North Alabama,xzhang6@una.edu
}

\begin{abstract}
The use of mobile payment technology is rapidly increasing. Using mobile payment enabled transportation apps is critical in realizing feasible and convenient mobile commerce transactions. The competition among mobile payment has created a "winner-take-all" phenomenon in the market due to strong network effects. As such, understanding user behavior in mobile payment is imperative for both academics and practitioners. This study addresses two research questions: (1) What are the factors that influence user switching behavior of mobile payment enabled transportation apps? (2) How do such factors influence user switching behavior? This research uses the push-pull-mooring (PPM) framework to investigate switching behavior. Based on an extensive literature review, accessibility concern and monetary rewards of alternatives are identified as push and pull factors, respectively, whereas inertia and privacy awareness are identified as mooring factors. A research model has been developed. This research can advance the understanding of user switching behavior of mobile payment enabled transportation apps and enrich the PPM framework by identifying specific contextual factors (i.e., accessibility concern and privacy awareness) of mobile payment enabled transportation apps. Our study can help transportation service providers identify advantages and disadvantages in keeping existing users and attracting new users.
\end{abstract}

Keywords: Mobile Payment Enabled Transportation Apps (MPETA), Switching Behavior, Push-PullMooring (PPM) Framework, Accessibility Concern, Privacy Awareness

\section{Introduction}

The use of mobile payment technology is rapidly increasing. A report by Allied Market Research (https://www.alliedmarketresearch.com/mobile-payments-market) valued the global mobile payment market at $\$ 1.48$ trillion in 2019 and it is projected to reach $\$ 12.06$ trillion by 2027 . Mobile payment refers to paying for goods, services, and bills using mobile devices which are using wireless or other communication technologies (Yang et al., 2012). With the development of mobile payment, vendors began to provide mobile payment enabled transportation apps (MPETA). Mobile payment is critical to transportation apps by facilitating convenient mobile commerce transactions (Mallat, 2007). Early adopters of these technologies include bike sharing services and online car-hailing services. In the last two years, some Chinese cities have installed mobile payment devices in urban public transportation services (buses and subways), and more Chinese cities are planning to do so. 


\section{Issues in Information Systems}

Volume 22, Issue 1, pp. 124-135, 2021

Mobile services are important from both the firms' and consumers' point of view because of the need for ubiquitous, universal, and simultaneous access to information and services and the possibility for unique and personalized exchange of information. As more people are using mobile payment, understanding user behavior is imperative for both academics and practitioners. The competition among mobile payment has created a "winner-take-all" phenomenon in the market due to strong network effects (Wang et al., 2019). The vendors of MPETA need to retain existing users, facilitate their continuance usage, and attract new users in a hyper-competitive environment. Understanding the mechanism of user switching behavior is critical for these vendors.

The life cycle of a specific technology generally includes three phases: adoption, usage, and switching or termination (Furneaux \& Wade, 2011). In this research, adoption and continuance usage may not describe user behavior when they face multiple alternative services. Thus, switching behavior may be suitable to describe user behavior in our research. User switching behavior has been investigated in various contexts but few research studies focus on MPETA. Given that there are differences among bus services, bike sharing services, and other transportation services, people may choose different services due to distinct characteristics of each transportation service. However, since mobile payment has unique characteristics, how users change their usage behavior in MPETA is still unclear.

This study addresses two research questions: (1) What are the factors that influence user switching behavior of mobile payment enabled transportation apps? (2) How do such factors influence user switching behavior? The paper proceeds as follows. In the literature review section, we will review literature to identify user behavior (adoption, continuance usage, and switching or termination), then we will construct a research model to be used to investigate use of MPETA. In the theoretical development section, we will focus on identifying the characteristics of transportation service, constructs, and factors that can impact user behavior in using MPETA. By investigating the relationships among constructs and factors, we can better understand the mechanisms of switching behavior in using MPETA.

\section{Literature review}

Although there are inherent differences in characteristics among different transportation service, we primarily focus on the use of MPETA. According to prior research studies, the life cycle of a specific technology generally includes three phases: adoption, usage, and switching or termination (Furneaux \& Wade, 2011). The first stream of literature review focuses on life cycle of mobile payment. Most of the prior research studies focus on the initial adoption of mobile payment, and the Technology Acceptance Model (TAM) and the Unified Theory of Acceptance and Use of Technology (UTAUT) are often used as theoretical bases (e.g., Johnson et al., 2018; Kim et al., 2010; Oliveira et al., 2016; Yang et al., 2012). These studies have examined a wide variety of factors that can impact mobile payment service adoption such as perceived ease of use, perceived usefulness, compatibility, social influence, and convenience. While regarding mobile payment as an innovation technology, researchers have used Diffusion of Innovations Theory (DOI) to identify factors that can influence adoption, such as relative advantage, security and trust, risk, and ubiquity (e.g., Johnson et al., 2018; Mallat, 2007; Oliveira et al., 2016).

For investigating the continuance usage perspective of mobile payments, the Expectation-Conformation Model is used widely to explain the continuous usage intention (e.g., Bhattacherjee, 2001). There are some studies that identify several antecedents of continuous usage intentions, such as service quality, cost rationality, satisfaction, perceived value, and habit. (e.g., Amoroso \& Chen, 2017; Cao et al., 2018; Chen \& Li, 2017; Zhou, 2013;). There is little attention paid to the switching behavior perspective of mobile payment (Wang et al., 2019), and this perspective has been largely overlooked (Turel, 2015). 


\section{Issues in Information Systems}

Volume 22, Issue 1, pp. 124-135, 2021

The adoption of mobile payment is found to be dynamic, depending on certain situational factors such as a lack of other payment methods or urgency (Mallat, 2007). In our study context, MPETA have been widely adopted (such as bike sharing service apps and taxi service apps), and the adoption and usage rate of mobile payments is higher in China than the rest of the world (https://www.statista.com/statistics/744944/mobilepayment-platforms-users/). Therefore, our research focuses on what factors influence users to choose a different mobile payment enabled transportation app, which is known as switching behavior. Identifying the different characteristics of MPETA and investigating them from a switching behavior perspective can provide valuable insight both to research and industry. This is an area that is not yet well understood or investigated in the literature.

The second phase of the literature review focuses on research studies of switching behavior and which frameworks and models are often adopted in such studies. User switching behavior has been investigated in various contexts such as social networking services (Maier et al., 2015), blog services (Hsieh et al., 2012), online auctions (Lin et al., 2012), e-commerce (Chang et al., 2017), and e-health care services (Lai \& Wang, 2015), and existing literature uses the push-pull-mooring (PPM) framework as the basic framework to investigate switching behavior. The PPM model serves as a theoretical underpinning to unveil the antecedents of user switching behavior, consisting of push factors that drive users away from incumbent services, pull factors that attract users to alternatives, and mooring factors that either hinder or facilitate switching behavior (Bansal et al., 2005). The PPM framework has been adapted to explore IS switching behavior regarding a plethora of technological artifacts, such as instant messaging service (Sun et al., 2017), mobile shopping (Lai et al., 2012; Lai \& Wang, 2015), and mobile payment (Wang et al., 2019).

Extant literature indicates that there is a paucity of the investigation of switching behavior utilizing the PPM framework in mobile payment context, thus we plan to examine user switching behavior of MPETA through the theoretical lens of the PPM framework. Most of the previous studies generally regard dissatisfaction, alternative attractiveness, and switching cost as the push, pull, and mooring factors, respectively. There are still specific contextual variables that may influence users switching behavior that need to be identified (Wang et al., 2019). For example, when users use MPETA, the vendors of mobile payment and transportation services require users to disclose highly confidential authentic personal information and location information to complete the service. For other services, such as social network services, users may provide fake personal information or location information to social network service providers, but they cannot do the same in MPETA. The differences may hamper user switching behavior, because users may not want to reveal personally identifiable information to numerous vendors. Other factors, such as accessibility concerns, are overlooked in prior research. Accessibility concerns are an important aspect of transportation services (Lättman et al., 2016), which may have significant effect on user switching behavior. In short, there is a research gap and thus a great opportunity to investigate push, pull, and mooring factors of user switching behavior in the specific context of MPETA.

\section{Theoretical development}

\section{Mobile Payment Enabled Transportation Apps}

Mobile payment is a process in which at least one phase of the transaction is conducted by a mobile device capable of securely completing a financial transaction over a mobile network, or by various wireless technologies (Yang et al., 2012). Compared with other mobile services, such as email, social networking, and instant messaging, mobile payments have unique characteristics (Wang et al., 2019). First, mobile payments require users to disclose highly personal information, such as bank account, date of birth, and identification number, phone number, and home address. If users want to use MPETA, they may need to share their location information (e.g., for bike sharing services). Personal information is used to process 


\section{Issues in Information Systems}

Volume 22, Issue 1, pp. 124-135, 2021

and complete such transactions. It is well known that mobile internet users are increasingly suffering from privacy invasions because of vulnerable mobile networks (Zhou, 2013). In other network services, users usually adopt some self-protective strategies and techniques to maintain their privacy. For example, users may provide false personal information while using social networking services and applications (Acquisti et al., 2015; Wang et al., 2017). However, these privacy protection strategies and techniques cannot be used in either mobile payment or transportation apps; this is because disclosing untruthful information or refusing to disclose personal information may lead to service failure or service termination.

Second, the competition among mobile payment is intense and fosters a "winner-take-all" phenomenon in the market due to strong network effects (Wang et al., 2019). Similarly, for MPETA, when a network effect is present, the value of a service increases as the number of users increases. Studies show that users are more likely to adopt a mobile payment application when it has more users (Holzer \& Ondrus, 2011). Third, compared with other mobile services, there are more formalities involved in the setup process of a mobile payment application. Energy, time, and effort are needed for a mobile payment application to function. As a result, users may continue using the incumbent service, even if it is not the best choice (Wang et al., 2019). Fourth, users of transportation services have traditionally been considered passive, but their role is changing from being isolated to being connected as well as being well informed; thus, such users have become active participants in the value-creating process (Vargo \& Lusch, 2008). Innovative technologies and services such as mobile payments represent key factors that can enhance the user experience for transportation applications, and thus user behavior will be dynamic by adopting these technologies (Di Pietro et al., 2015). Based on this argument, user switching behavior of transportation apps will be magnified when the apps are enabled by mobile payment.

In transportation services, accessibility is a key factor that has significant effect on user experience and can influence user behavior (Lättman et al., 2016). From the user perspective, accessibility is the extent to which land-use and transport systems enable individuals to reach activities or destinations by one mode or a combination of modes at various times of the day (Di Pietro et al., 2015; van Wee, 2013). In this context, accessibility is transportation service accessibility by using mobile payment. Different vendors of MPETA provide different transportation services, and accessibility of these services may be different for users. The differences in accessibility could be key factors which influence user switching behavior. For example, bike sharing services such as Mobike and Hellobike provide different places for users to receive their bike services; if the accessibility of one bike sharing service does not meet user expectations, the users may change to another bike sharing service.

\section{The Push-Pull-Mooring Framework and Switching Behavior}

The PPM framework is the dominant paradigm that has been used in research studies focusing on switching behavior (Bansal et al., 2005), suggesting that user migration decisions to move from one service application to another is affected by push, pull, and mooring factors. Push factors, often referred to as stressors, are defined as the forces that drive people away from current products or services, while pull factors or attractors reflect the positive factors of the alternatives. Since switching is a complex decision, mooring factors represent the supplementary constraints that facilitate or hamper behavior (Wang et al., 2019). The PPM framework explains why people change from one service application to another for a certain period (Wang et al., 2019). The PPM framework has been used and validated in various IT contexts, such as instant messaging service (Sun et al., 2017), mobile shopping (Lai et al., 2012; Lai \& Wang, 2015), and mobile payment (Wang et al., 2019). Considering the unique characteristics of MPETA and previous research studies, we propose a host of critical factors that facilitate or hamper user switching behavior. 


\section{Issues in Information Systems}

Volume 22, Issue 1, pp. 124-135, 2021

\section{Push Factor: Accessibility Concern}

As discussed above, accessibility is a key factor that can influence user decisions on transportation services. If users feel/believe/perceive that their MPETA cannot be accessed conveniently and easily, they may decide to change/switch from the incumbent transportation service application to alternative ones. Accessibility concern refers to user concerns on accessibility to MPETA. Previous studies on switching behavior have used dissatisfaction, fatigue with incumbent service, and privacy concerns (Maier et al., 2015; Sun et al., 2017; Wang et al., 2019) as push factors. Even using mobile payment, transportation services still must be easy to access physically for users. Therefore, we identify accessibility concern as a critical push factor that drives users away from the incumbent service toward an alternative.

\section{Pull Factor: Monetary Rewards of Alternatives}

Monetary rewards are used as a pull factor and validated by previous research studies (Wang et al., 2019). Compared with users of other mobile applications such as social networking, online gaming, and instant messaging, mobile payment users are more sensitive to monetary rewards (Wang et al., 2019). Similarly, users of MPETA are sensitive to monetary rewards. Generally, to quickly establish a massive user network, granting newly adopted users with monetary rewards has been found to be one of most broadly used mechanisms to attract potential users. For example, in certain locations, Apple Pay awards new users a certain percentage cash back on each transaction for bus services. Users may switch to alternatives if they are lured by such monetary rewards (Schierz et al., 2010). Thus, we consider monetary rewards of alternatives as an important pull factor.

\section{Mooring Factors: Inertia and Privacy Awareness}

Mooring factors can influence users to forgo switching, even if there are significant push and pull factors for them to do so (Bansal et al., 2005). This unwillingness may be caused by behavioral inertia (Limayem et al., 2007), which is user's conscious continuance of the status quo rather than switching to potentially better alternatives (Kim \& Kankanhlli, 2009). Individuals tend to rely on their past behavior, instead of current deliberations, to guide their current and future choices, even if the benefits of alternatives outweigh those of the incumbent service (Polites \& Karahanna, 2012). For example, as we discussed above, there are many formalities that need to be completed when users register for MPETA. If users perceive these formalities to be too much effort, they may continue to use their incumbent service. This inertia can prevent users from making service-switching decisions.

In the existing research, privacy concerns are identified as a push factor in switching behavior (Wang et al., 2019). Users may worry about their privacy being protected by vendors and thus may switch their incumbent service to another service, perceived to be more secure. On the other hand, users may refrain from switching to a new transport application, in order to limit the number of applications that have access to their private information. In our context, users need to share much more detailed and authentic personal information such as identification number, bank account, and personal location with MPETA vendors to complete the whole service process. Users are aware that they have shared personal information with one service provider, and they may not want to share their information with another provider even if they feel the incumbent service is not as good. In this context, privacy awareness refers to user awareness of their privacy information being shared with service providers and mobile payment vendors. This awareness could prevent users from making the decision to change services. Therefore, we consider both inertia and privacy awareness as mooring factors to better understand the underlying mechanisms of mooring effects. 


\section{Research model and development of hypotheses}

Based on the arguments above, we use the PPM model to hypothesize that push, pull, and mooring factors influence switching behavior directly. Following previous research studies (e.g., Lai \& Wang, 2015; Wang et al., 2019), mooring factors are further hypothesized to moderate the main effects of push and pull factors on switching behavior. The research model proposed in this section is showed in Figure 1.

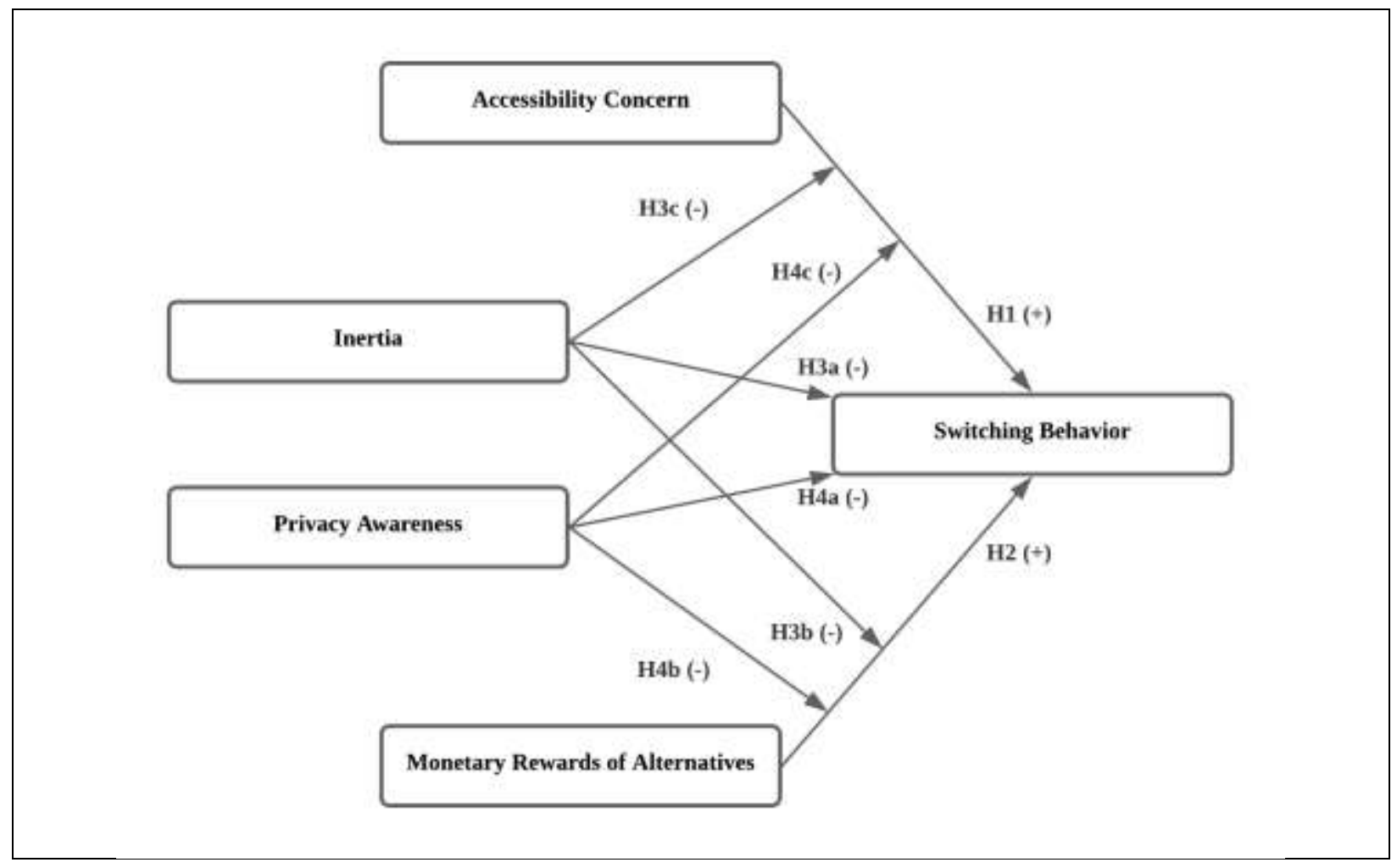

Figure 1. Research Model

\section{Accessibility Concern and Switching Behavior}

As we discussed above, accessibility concern refers to user concerns on accessibility to MPETA. As a push factor, accessibility concern has a positive effect on switching behavior. This means users who are more concerned about the accessibility of their incumbent transportation service are more likely to switch incumbent service to alternative one. Thus, we propose:

$\mathrm{H}_{1}$ : Accessibility concerns are positively associated with switching behavior of mobile payment enabled transportation apps.

\section{Monetary Rewards of Alternatives and Switching Behavior}

The monetary rewards of alternatives refer to tangible benefits, such as cash bonuses, coupons, discounts, and promotion deals provided by alternative MPETA. Any social behavior may result in both costs and benefits (Cropanzano \& Mitchell, 2005). Users of MPETA may compare monetary rewards of alternatives with sunk cost of switching. The sunk cost of switching includes the benefits of incumbent service and the time and effort that have been devoted to incumbent service, as well as affective commitment (Ray et al., 


\section{Issues in Information Systems}

Volume 22, Issue 1, pp. 124-135, 2021

2011). Compared with sunk cost, the higher monetary rewards that an alternative provides, the more likely it is for users to switch incumbent service to an alternative. Thus, we propose:

$\mathrm{H}_{2}$ : The monetary rewards of alternatives are positively associated with the switching behavior of mobile payment enabled transportation apps.

\section{Inertia and Switching Behavior}

The phenomenon that individuals prefer to maintain the status quo instead of switching to new, potentially better alternative is called status quo bias. Inertia is termed as the manifestation of the status quo bias, and an important resistance factor for switching behavior (Pilites \& Karahanna, 2012). The concept of inertia includes three dimensions: behavioral-based, cognitive-based, and affective-based. One may keep using a service simply because of behavioral-based inertia. Cognitive-based inertia means that individuals may continue using incumbent service even if they are aware that it is not the best one. Affective-based inertia forms as individuals enjoy using the incumbent service (Wang et al., 2019). Thus, inertia may result in resistance to change. Previous studies have found that inertia is negatively related to the perceived usefulness and perceived ease of use of an alternative service (Amoroso \& Lim, 2017; Li et al., 2016). Consequently, inertia causes users to perceive an alternative as less attractive (Wang et al., 2019). Therefore, inertia makes users to prefer to stay with an incumbent service, even if they have realized the advantages of alternatives. Base on this argument, we propose the following hypothesis:

$\mathrm{H}_{3 \mathrm{a}}$ : Inertia is negatively associated with the switching behavior of mobile payment enabled transportation apps.

As we discussed above, inertia could make an alternative less attractive for users. Thus, the influence of positive pull factors, such as monetary rewards, on switching behaviors will be weakened by the effects of inertia.

$\mathrm{H}_{3 b}$ : Inertia weakens the positive relationship between monetary rewards of alternatives and switching behavior.

Additionally, one may continue using an incumbent service even if they are aware that it is not the best one. In our context, even if inertial users are aware that the accessibility of transportation services is not as good, they may still want to stay with their incumbent service. In other words, the positive effect of accessibility concern on switching behavior decreases as user inertia increases. Thus, we propose the following hypothesis:

$\mathrm{H}_{3 \mathrm{c}}$ : Inertia weakens the positive relationship between accessibility concerns and switching behavior.

\section{Privacy Awareness and Switching Behavior}

Although privacy concern is identified as a push factor in switching behavior in previous research, privacy awareness is identified as mooring factors in our context. Privacy awareness refers to user awareness of how much of their personal/privacy information is shared with service providers and mobile payment vendors. Because MPETA need more personal information to complete services and transactions, users are aware that they have shared much information with one service provider, and they may not want to share their information with another provider. If we regard "providing much personal information" as sunk cost, then this awareness will be negatively associated with switching behavior. Therefore, we propose: 


\section{Issues in Information Systems}

Volume 22, Issue 1, pp. 124-135, 2021

$\mathrm{H}_{4 \mathrm{a}}$ : Privacy awareness is negatively associated with switching behavior of mobile payment enabled transportation apps.

Users are aware that they have provided personal information to the service vendor, and therefore they may not want to provide such information to another vendor, even if the alternative provides monetary rewards or the accessibility of incumbent service is not as good. As such, this awareness may weaken the push and pull effect on switching behavior. As we mentioned above, mooring factors are hypothesized to moderate the main effects of push and pull factors on switching behavior. In the same vein, we propose the following hypotheses:

$\mathrm{H}_{4 \mathrm{~b}}$ : Privacy awareness weakens the positive relationship between monetary rewards of alternatives and switching behavior.

$\mathrm{H}_{4 c}$ : Privacy awareness weakens the positive relationship between accessibility concerns and switching behavior.

\section{Methodology}

\section{Survey and Data Collection}

For this research, we plan to use a survey questionnaire to collect data. In addition to demographic and research model related data, we will also gather revenue information of transportation service companies (public transportation service companies, bike sharing service vendors, etc.) and a history of when a transportation app was enabled by mobile payment. This historical data will be collected using secondary data. We believe this result can be used in an event study fashion to verify the results of the primary (survey) data collection method.

\section{Variables and Measurements}

For privacy awareness, we focus on whether the users are aware they have shared private information with services and mobile payment vendors (we may ask users questions like, "Do you think you have shared significant personal information with MPETA?"). Besides privacy awareness, the measurement items of our survey will be drawn from validated scales in previous research studies. The items for accessibility concern will be adopted from Lättman et al. (2016). The items for monetary rewards of alternatives will be adopted from Zhao et al. (2012). We will use three dimensions (affective-based, behavioral based, and cognitive-based) and nine items to measure inertia (Polites and Karahanna 2012). All these items will be measured on a 7-point Likert scale ranging from "Strongly Disagree = 1" to "Strongly Agree = 7." All constructs and measurement items are listed in Table 1 below. Control variables such as gender, age, monthly income, length of use, and education will also be collected. 
Table 1. Constructs and Measurement Items

\begin{tabular}{|c|c|}
\hline Constructs & Measurement Items \\
\hline Privacy awareness & Awareness of private information shared with service vendors. \\
\hline \multirow[t]{3}{*}{ Accessibility concern } & Ease of travel. \\
\hline & $\begin{array}{l}\text { The ability to live the life one wants ("If this transport service was } \\
\text { my only mode of travel, I'd be able to continue living the way I } \\
\text { want"). }\end{array}$ \\
\hline & $\begin{array}{l}\text { Accessibility to activities ("It's possible to do the activities I prefer } \\
\text { with this transport service" and "Access to my preferred activities is } \\
\text { satisfying with this transport service). }\end{array}$ \\
\hline $\begin{array}{l}\text { Monetary rewards of } \\
\text { alternatives }\end{array}$ & $\begin{array}{l}\text { Provide monetary rewards (e.g., coupons, discounts, } \\
\text { and free products) to new users. }\end{array}$ \\
\hline \multirow[t]{4}{*}{ Inertia-affective-based } & ...will continue using incumbent service because... \\
\hline & it would be stressful to change. \\
\hline & it is part of my normal life. \\
\hline & I enjoy doing so. \\
\hline \multirow[t]{4}{*}{ Inertia-behavioral-based } & ...will continue using incumbent service ... \\
\hline & because it is what I have always been doing. \\
\hline & because it is part of my normal life. \\
\hline & because I have done so regularly in the past. \\
\hline \multirow[t]{4}{*}{ Inertia-cognitive-based } & ...will continue using incumbent service ... \\
\hline & even though I know it is not the best service. \\
\hline & even though I know the service is not very easily to use. \\
\hline & even though I know the service is not very effective. \\
\hline
\end{tabular}

\section{Discussion}

\section{Theoretical Contributions}

First, our study advances the understanding of switching behavior of MPETA. As we discussed above, the existing studies primarily focus on user adoption and continuous usage, and few on user switching behavior. MPETA have unique characteristics that may influence switching behavior. Thus, investigating user switching behavior within such context may add new knowledge to the IS field. Second, this study may enrich the PPM framework by identifying specific contextual variables, such as privacy awareness and accessibility concern of MPETA, which may influence user switching behavior.

\section{Practical Contributions}

Our findings may help industry understand user switching behavior of MPETA. Our study may help companies identify their advantages and disadvantages in keeping current users and attracting new users. Thus, these companies may improve their strategies and services to achieve competitive advantages.

\section{Limitations and Future Research}

Our research has several limitations. First, our research context focuses on Chinese MPETA since such services have been massively adopted in China. The result may be different in different cultures and environments. For instance, privacy awareness may be a push factor instead of mooring factor in western countries since people in such cultures are more sensitive to personal information sharing. Second, we did 


\section{Issues in Information Systems}

Volume 22, Issue 1, pp. 124-135, 2021

not take characteristics of different transportation modes (such as bicycle services, bus services, and taxi services) into consideration in our research model. User behavior may be different based on what kind of transportation modes they use. Hence, future research can address these limitations and investigate the impact of cultural factors and characteristics of different transportation services on switching behavior of MPETA.

\section{References}

Acquisti, A., Brandimarte, L., \& Loewenstein, G. (2015). Privacy and human behavior in the age of information. Science, 347(6221), 509-514.

Amoroso, D. L., \& Chen, Y. (2017). Constructs affecting continuance intention in consumers with mobile financial apps: A dual factor approach. Journal of Information Technology Management, 28(3), $1-24$.

Amoroso, D., \& Lim, R. (2017). The mediating effects of habit on continuance intention. International Journal of Information Management, 37(6), 693-702.

Bansal, H. S., Taylor, S. F., \& James, Y. S. (2005). "Migrating” to new service providers: Toward a unifying framework of consumers' switching behaviors. Journal of the Academy of Marketing Science, 33, 96-115.

Bhattacherjee, A. (2001). Understanding information systems continuance: An expectation-confirmation model. MIS Quarterly, 25(3), 351-370.

Cao, X., Yu, L., Liu, Z., Gong, M., \& Adeel, L. (2018). Understanding mobile payment users' continuance intention: A trust transfer perspective. Internet Research, 28(2), 456-476.

Chang, H. H., Wong, K. H., \& Li, S. Y. (2017). Applying push-pull-mooring to investigate channel switching behaviors: M-shopping self-efficacy and switching costs as moderators. Electronic Commerce Research and Applications, 24, 50-67.

Chen, X., \& Li, S. (2017). Understanding continuance intention of mobile payment services: An empirical study. Journal of Computer Information Systems, 57(4), 287-298.

Cropanzano, R., \& Mitchell, M. S. (2005). Social exchange theory: An interdisciplinary review. Journal of Management, 31(6), 874-900.

Di Pietro, L., Mugion, R. G., Mattia, G., Renzi, M. F., \& Toni, M. (2015). The integrated model on mobile payment acceptance (IMMPA): An empirical application to public transport. Transportation Research Part C: Emerging Technologies, 56, 463-479.

Furneaux, B., \& Wade, M. R. (2011). An exploration of organizational level information systems discontinuance intentions. MIS Quarterly, 35(3), 573-598.

Holzer, A., \& Ondrus, J. (2011). Mobile application market: A developer's perspective. Telematics and Informatics, 28(1), 22-31. 


\section{Issues in Information Systems}

Volume 22, Issue 1, pp. 124-135, 2021

Hsieh, J.-K., Hsieh, Y.-C., Chiu, H.-C., \& Feng, Y.-C. (2012). Post-adoption switching behavior for online service substitutes: A perspective of the push-pull-mooring framework. Computers in Human Behavior, 28(5), 1912-1920.

Johnson, V. L., Kiser, A., Washington, R., \& Torres, R. (2018). Limitations to the rapid adoption of Mpayment services: Understanding the impact of privacy risk on M-Payment services. Computers in Human Behavior, 79, 111-122.

Kim, H.-W., \& Kankanhalli, A. (2009). Investigating user resistance to information systems implementation: A status quo bias perspective. MIS Quarterly, 33(3), 567-582.

Kim, C., Mirusmonov, M., \& Lee, I. (2010). An empirical examination of factors influencing the intention to use mobile payment. Computers in Human Behavior, 26(3), 310-322.

Lai, J.-Y., Debbarma, S., \& Ulhas, K. R. (2012). An empirical study of consumer switching behavior towards mobile shopping: A push-pull-mooring model. International Journal of Mobile Communications, 10(4), 386-404.

Lai, J.-Y., \& Wang, J. (2015). Switching attitudes of Taiwanese middle-aged and elderly patients toward cloud healthcare services: An exploratory study. Technological Forecasting and Social Change, 92, 155-167.

Lättman, K., Friman, M., \& Olsson, L. E. (2016). Perceived accessibility of public transport as a potential indicator of social inclusion. Social Inclusion, 4(3), 36-45.

Li, J., Liu, M., \& Liu, X. (2016). Why do employees resist knowledge management systems? An empirical study from the status quo bias and inertia perspectives. Computers in Human Behavior, $65,189-200$.

Limayem, M., Hirt, S. G., \& Cheung, C. M. K. (2007). How habit limits the predictive power of intention: The case of information systems continuance. MIS Quarterly, 31(4), 705-737.

Lin, T.-C., Cheng, H. K., Wang, F.-S., \& Chang, K.-J. (2012). A study of online auction sellers' intention to switch platform: The case of Yahoo!Kimo versus Ruten_eBay. Decision Sciences, 43(2), 241272.

Maier, C., Laumer, S., Eckhardt, A., \& Weitzel, T. (2015). Giving too much social support: Social overload on social networking sites. European Journal of Information Systems, 24(5), 447-464.

Mallat, N. (2007). Exploring consumer adoption of mobile payments - A qualitative study. Journal of Strategic Information Systems, 16(4), 413-432.

Oliveira, T., Thomas, M., Baptista, G., \& Campos, F. (2016). Mobile payment: Understanding the determinants of customer adoption and intention to recommend the technology. Computers in Human Behavior, 61, 404-414.

Polites, G. L., \& Karahanna, E. (2012). Shackled to the status quo: The inhibiting effects of incumbent system habit, switching costs, and inertia on new system acceptance. MIS Quarterly, 36(1), 2142. 


\section{Issues in Information Systems}

Volume 22, Issue 1, pp. 124-135, 2021

Ray, S., Kim, S. S., \& Morris, J. G. (2011). Online users' switching costs: Their nature and formation. Information Systems Research, 23(1), 197-213.

Schierz, P. G., Schilke, O., \& Wirtz, B. W. (2010). Understanding consumer acceptance of mobile payment services: An empirical analysis. Electronic Commerce Research and Applications, 9(3), 209-216.

Sun, Y., Liu, D., Chen, S., Wu, X., Shen, X.-L., \& Zhang, X. (2017). Understanding users' switching behavior of mobile instant messaging applications: An empirical study from the perspective of push-pull-mooring framework. Computers in Human Behavior, 75, 727-738.

Turel, O. (2015). Quitting the use of a habituated hedonic information system: A theoretical model and empirical examination of Facebook users. European Journal of Information Systems, 24(4), 431446.

Van Wee, B. (2013). Urban form and transport accessibility. Journal of Environmental Policy \& Planning, 15(2), 323-324.

Vargo, S. L., \& Lusch., R. F. (2008). Service-dominant logic: Continuing the evolution. Journal of the Academy of Marketing Science, 36(1), 1-10.

Wang, L., Yan, J., Lin, J., \& Cui, W. (2017). Let the users tell the truth: Self-disclosure intention and selfdisclosure honesty in mobile social networking. International Journal of Information Management, 37(1), 1428-1440.

Wang, L., Luo, X., Yang, X., \& Qiao, Z. (2019). Easy come or easy go? Empirical evidence on switching behaviors in mobile payment applications. Information \& Management, 56(7), 103-150.

Yang, S., Lu, Y., Gupta, S., Cao, Y., \& Zhang, R. (2012). Mobile payment services adoption across time: An empirical study of the effects of behavioral beliefs, social influences, and personal traits. Computers in Human Behavior, 28(1), 129-142.

Zhao, L., Lu, Y., \& Gupta, S. (2012). Disclosure intention of location-related information in locationbased social network services. International Journal of Electronic Commerce, 16(4), 53-90.

Zhou, T. (2013). An empirical examination of continuance intention of mobile payment services. Decision Support Systems, 54(2), 1085-1091. 